OPEN ACCESS

Edited by:

Slobodan Paessler,

University of Texas Medical Branch,

United States

Reviewed by:

Florian Krammer,

Icahn School of Medicine at Mount

Sinai, United States

Veljko Veljkovic,

Institute of Nuclear Sciences Vinca,

Serbia

*Correspondence:

Elsayed M. Abdelwhab

sayed.abdel-whab@fli.de;

sayedabdelwhab@yahoo.com

tThese authors have contributed equally to this work.

Specialty section:

This article was submitted to

Virology,

a section of the journal

Frontiers in Microbiology

Received: 18 January 2018 Accepted: 08 March 2018

Published: 27 March 2018

Citation:

Salaheldin AH, Kasbohm E, El-Naggar H, Ulrich R, Scheibner D, Gischke M, Hassan MK, Arafa A-SA,

Hassan WM, Abd El-Hamid HS,

Hafez HM, Veits J, Mettenleiter TC and Abdelwhab EM (2018) Potential Biological and Climatic Factors That

Influence the Incidence and

Persistence of Highly Pathogenic H5N1 Avian Influenza Virus in Egypt.

Front. Microbiol. 9:528.

doi: 10.3389/fmicb.2018.00528

\section{Potential Biological and Climatic Factors That Influence the Incidence and Persistence of Highly Pathogenic H5N1 Avian Influenza Virus in Egypt}

\author{
Ahmed H. Salaheldin ${ }^{1,2,37}$, Elisa Kasbohm ${ }^{1,4 t}$, Heba El-Naggar ${ }^{5 \dagger}$, Reiner Ulrich ${ }^{1}$, \\ David Scheibner ${ }^{1}$, Marcel Gischke ${ }^{1}$, Mohamed K. Hassan ${ }^{6}$, Abdel-Satar A. Arafa ${ }^{6}$, \\ Wafaa M. Hassan ${ }^{6}$, Hatem S. Abd El-Hamid ${ }^{7}$, Hafez M. Hafez ${ }^{2}$, Jutta Veits ${ }^{1}$, \\ Thomas C. Mettenleiter ${ }^{1}$ and Elsayed M. Abdelwhab ${ }^{1 *+}$
}

\begin{abstract}
${ }^{1}$ Institute of Molecular Virology and Cell Biology, Friedrich-Loeffler-Institut, Federal Research Institute for Animal Health, Greifswald-Insel Riems, Germany, ${ }^{2}$ Institute of Poultry Diseases, Free University of Berlin, Berlin, Germany, ${ }^{3}$ Department of Poultry Diseases, Faculty of Veterinary Medicine, Alexandria University, Edfina, Egypt, ${ }^{4}$ Institute of Mathematics and Computer Science, University of Greifswald, Greifswald, Germany, ${ }^{5}$ Veterinary Serum and Vaccine Research Institute, Cairo, Egypt, ${ }^{6}$ National Laboratory for Veterinary Quality Control on Poultry Production, Animal Health Research Institute, Giza, Egypt, ${ }^{7}$ Faculty of Veterinary Medicine, Damanhur University, Damanhur, Egypt
\end{abstract}

Highly pathogenic H5N1 avian influenza virus (A/H5N1) of clade 2.2.1 is endemic in poultry in Egypt where the highest number of human infections worldwide was reported. During the last 12 years the Egyptian $\mathrm{A} / \mathrm{H} 5 \mathrm{~N} 1$ evolved into several genotypes. In 2007-2014 vaccinated poultry suffered from antigenic drift variants of clade 2.2.1.1 and in 2014/2015 an unprecedented upsurge of $\mathrm{A} / \mathrm{H} 5 \mathrm{~N} 1$ clade 2.2.1.2 occurred in poultry and humans. Factors contributing to the endemicity or re-emergence of $\mathrm{A} / \mathrm{H} 5 \mathrm{~N} 1$ in poultry in Egypt remain unclear. Here, three potential factors were studied: climatic factors (temperature, relative humidity, and wind speed), biological fitness in vitro, and pathogenicity in domestic Pekin and Muscovy ducks. Statistical analyses using negative binomial regression models indicated that ambient temperature in winter months influenced the spread of $\mathrm{A} / \mathrm{H} 5 \mathrm{~N} 1$ in different geographic areas analyzed in this study. In vitro, at 4 and $56^{\circ} \mathrm{C}$ 2.2.1.1 and recent 2.2.1.2 viruses were more stable than other viruses used in this study. Further, Pekin ducks were more resistant than Muscovy ducks and the viruses were excreted for up to 2 weeks post-infection assuming a strong role as a reservoir. Taken together, ambient temperature in winter months potentially contributes to increasing outbreaks in some regions in Egypt. Heat stability of clade 2.2.1.1 and recent 2.2.1.2 viruses probably favors their persistence at elevated temperatures. Importantly, asymptomatically infected Pekin ducks may play an important role in the spread of avian and human-like $\mathrm{A} / \mathrm{H} 5 \mathrm{~N} 1$ in Egypt. Therefore, control measures including targeted surveillance and culling of silently infected Pekin ducks should be considered.

Keywords: H5N1, highly pathogenic avian influenza virus, poultry, meteorological factors, epidemiology, ducks, clade 2.2.1, Egypt 


\section{INTRODUCTION}

Highly pathogenic avian influenza virus (HPAIV) H5N1 (A/H5N1) caused enormous economic losses in poultry in many countries worldwide and genetically diversified into 10 clades and several subclades since 1996/1997 (Smith et al., 2015). Clade 2 viruses spread from China to Europe and Africa since 2003, and eventually became endemic in poultry in Egypt and several Asian countries. Since 2006, Egyptian A/H5N1 of clade 2.2.1 have diversified into several genetic groups. Most of these phylogroups disappeared but two major clades circulated for several years (Abdelwhab et al., 2016). Clade 2.2.1.1 represented antigenic-drift variants, which were primarily isolated from vaccinated commercial poultry leading to three human infections so far according to the official reports to the World Health Organization. These viruses appeared in early 2007 and predominated in 2008-2010 challenging the efficacy of the highly diverse $\mathrm{H} 5$ vaccines in Egypt. In 2011-2014, the prevalence of 2.2.1.1 viruses dramatically decreased and they are most likely extinct by now (Abdelwhab et al., 2016; El-Shesheny et al., 2017; Rohaim et al., 2017). The second clade are 2.2.1.2 viruses which circulated in non-vaccinated backyard birds and were introduced into small-scale farmed poultry since early 2008 . The vast majority of infected humans were infected by this genotype (Younan et al., 2013). In 2014/2015, an unprecedented upsurge of 2.2.1.2 was reported in poultry and humans marking Egypt as the country with the highest number of human infections with A/H5N1 worldwide (Arafa et al., 2015; WHO, 2017). These viruses spread to neighboring countries posing a serious threat in the Middle East (Naguib et al., 2016a; Salaheldin et al., 2017). Driving forces for the emergence, extinction or spread of A/H5N1 clades in Egypt are not well-studied except for the massive application of vaccines and antivirals in poultry (AbdelMoneim et al., 2011; Cattoli et al., 2011; Abdelwhab et al., 2016; El-Shesheny et al., 2016; Naguib et al., 2016b).

The spread of influenza viruses may be influenced by several factors related to environment, virus, and host. Previous research has shown that meteorological factors, biological fitness, and/or domestic ducks play significant roles in shaping the spread of influenza viruses (Li et al., 2004, 2015). Apart from the seasonal incidence of human influenza viruses, there is a paucity of information about the impact of climatic factors on the spread and course of influenza viruses' infection in domestic birds. Studies on wild bird populations showed that the regional prevalence of avian influenza viruses (AIV) may follow a seasonal pattern and can be influenced by climatic conditions (Gilbert et al., 2008a; Herrick et al., 2013; Ferenczi et al., 2016).

\footnotetext{
Abbreviations: A/H5N1, Highly pathogenic avian influenza virus H5N1; A549, Adenocarcinomic human alveolar basal epithelial cells; AIC, Akaike information criterion; AIV, Avian influenza viruses; BSA, Bovine serum albumin; CBS, Citrate-buffered saline; CEK, Chicken embryo kidney cells; dpi, days postinoculation; ECE, Embryonated chicken eggs; FLI, Friedrich-Loeffler-Institut; HA test, hemagglutination test; HA, hemagglutinin; HPAIV, Highly pathogenic avian influenza virus; MDCKII, Madin-Darby canine kidney cells II; NA, Neuraminidase; NLQP: National Laboratory for Veterinary Quality Control on Poultry Production; PFU, Plaque-forming unit; SA, Sialic acid; SPF, Specific pathogen free; TRBCs, Turkey erythrocytes.
}

However, little is known about the correlation and the impact of climatic factors on introduction and persistence of HPAIV in domestic poultry. Biological fitness (e.g., stability in harsh niches, rapid replication, or spread) may be advantageous for virus perpetuation outside the host or increase adaptation to birds and human (Terregino et al., 2009). The role of domestic ducks for generation and persistence of $\mathrm{A} / \mathrm{H} 5 \mathrm{~N} 1$ in Asian countries is wellstudied. In contrast to the high mortality in chickens, domestic ducks were considered a "Trojan horse" because they are usually infected without exhibiting clinical signs or mortality (Chen et al., 2004; Hulse-Post et al., 2005; Gilbert et al., 2006; Songserm et al., 2006) enabling silent spread of the virus to other hosts (e.g., chickens, humans) (Kim et al., 2009; Lebarbenchon et al., 2010). In Egypt, about 40 million ducks raised in backyard and commercial farms where Pekin and Muscovy ducks are the most prevalent breeds (Hassan et al., 2013). A/H5N1 was isolated from asymptomatic domestic ducks in hot summer seasons in some localities in Egypt (Hassan et al., 2013). Also, viruses isolated from different organs of ducks were more genetically diverse than those isolated from chickens (Watanabe et al., 2011a), suggesting a role for ducks in perpetuating the endemicity of $\mathrm{A} / \mathrm{H} 5 \mathrm{~N} 1$ in Egypt.

Here, we investigated three potential factors which could affect the evolution of A/H5N1 in poultry in Egypt: the climatic factors from October to March where the incidence of outbreaks rises, the variation in biological fitness of 2.2.1.1 and 2.2.1.2 viruses in different cells, and the role of Pekin and Muscovy ducks as a reservoir for two representative viruses from both major clades isolated from poultry in Egypt.

\section{MATERIALS AND METHODS \\ Climatic and Epidemiological Data Collection and Processing}

The daily data on temperature (minimum, maximum, and average), relative humidity, and wind speed were retrieved from Weather Underground Website (Dugas et al., 2013). Data were collected for 10 seasons from 2006 to 2015. Each season lasted from the 1st of October to 31st of March of the following year, when the incidence of outbreaks peaked according to previous surveillance (Arafa A. et al., 2012; Arafa A. S. et al., 2012; El-Zoghby et al., 2013; Arafa et al., 2015; Kayali et al., 2016). For example, the "2006-2007" season represented the data from 01.10.2006 to 31.03.2007. The means and standard deviations for each month were calculated and used for analysis. Four governorates namely Alexandria, Cairo, Minya, and Luxor (ordered from north to south) were selected based on their geographic location, climate zones, and variable number of A/H5N1 outbreaks (Figure 1). While Alexandria is situated close to the Mediterranean coast and therefore characterized by a maritime climate with higher precipitation and moderate temperatures, following the river Nile further south the climate changes into a hot desert climate with little to no precipitation and high temperatures. The total number of $\mathrm{A} / \mathrm{H} 5 \mathrm{~N} 1$ outbreaks per month was summarized for each season based on the official reports of national surveillance conducted by the Egyptian 


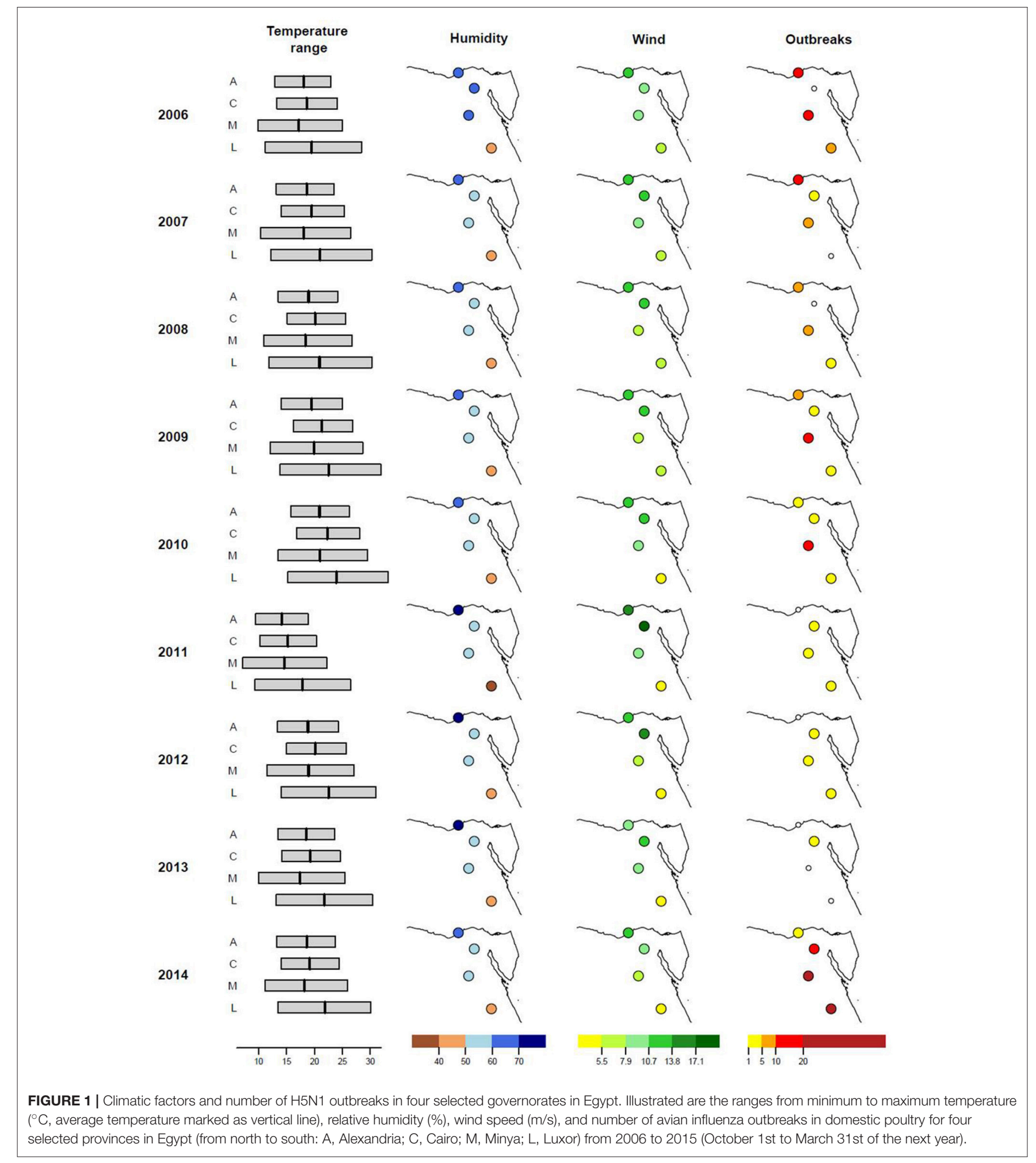

National Laboratory for Veterinary Quality Control on Poultry Production (NLQP) and reported to the World Organization for Animal Health (OIE) and to Food and Agriculture Organization of the United Nations (FAO). Five unreported cases, which were detected in a retrospective surveillance from vaccinated birds, were also included in the analysis. The effect of selected climate parameters on the number of outbreaks in each region and all-over Egypt was analyzed as described below. 
The correlation between each of the climate factors and the reported number of outbreaks was calculated as Spearman's rank correlation coefficient for the whole of Egypt and also for each of the governorates. Furthermore, negative binomial regression models were used to assess the combined contribution of several climate factors on the observed number of outbreaks per governorate. We investigated a "full" model, which includes regional effects and all climate factors as explanatory variables. Since climate factors are interrelated, significant effects of these variables might be obscured in the full model. Thus, a "reduced" model with fewer variables was derived from the full model by stepwise backward elimination minimizing the Akaike information criterion (AIC). AIC was chosen for model selection for the reason that this criterion evaluates the goodness of fit (based on the likelihood) and simultaneously takes the number of explanatory variables into account. Additionally, we investigated a model based solely on the available climate variables without correcting for regional differences and an additional model which includes only regional effects and hence assumes that the observed numbers of outbreaks follow a random (climate independent) pattern.

\section{Viruses and Cells}

To study the biological fitness of different A/H5N1 clades in Egypt (2.2.1, 2.2.1.1, and 2.2.1.2), six viruses were obtained from the repository of the Friedrich-Loeffler-Institut (FLI), Germany as summarized in Table 1. Two viruses belonged to the clade 2.2.1, A/chicken/Egypt/083-NLQP/2008(H5N1) (designated 2.2.1-A), A/chicken/Egypt/0815-NLQP/2008(H5N1) (designated 2.2.1-B), one virus belonged to the early clade 2.2.1.2 (A/duck/Egypt/0897-NLQP/2008(H5N1) (designated 2.2.1.2-A), one virus of clade 2.2.1.2 originate from the recent upsurge in 2014/2015 A/turkey/Egypt/AR238-SD177NLQP/2014(H5N1) (designated 2.2.1.2-C) and a putative predecessor virus from 2013 A/chicken/Egypt/NLQP7FL-AR747/2013(H5N1) (designated 2.2.1.2-B). The last virus belonged to clade 2.2.1.1 A/chicken/Egypt/0879-NLQP/2008(H5N1) (designated 2.2.1.1) which was extensively studied as an $\mathrm{A} / \mathrm{H} 5 \mathrm{~N} 1$ immune-escape variant in vaccinated chickens (Abdelwhab et al., 2011; Grund et al., 2011). It is antigenically distinct from clade
2.2.1.2 viruses. Furthermore, in addition to 2.2.1.1 virus, A/turkey/Egypt/R1507/2016 (designated 2.2.1.2-D) isolated in 2016 from a vaccinated turkey flock (Salaheldin et al., 2017) was used for infection of Pekin and Muscovy ducks. The 2.2.1.2-D virus was not available when the project started. Not all in-vitro characterization experiments were done for this virus and therefore these data (except for receptor binding) are not provided. The 2.2.1.2-D was used for the infection of ducks because it was the most recent Egyptian isolate from clade 2.2.1.2. Lastly, A/PR/8/1934(H1N1) (designated PR8), a human virus, and A/quail/California/D113023808/2012(H4N2) were used as controls in receptor binding assays. The $\mathrm{H} 4 \mathrm{~N} 2$ virus was kindly provided by Beate Crossley, UC Davis. Viruses were inoculated into the allantoic cavity of specific pathogen free (SPF) embryonated chicken eggs (ECE) for 3-5 days. Chorioallantoic fluid (AF) was tested by hemagglutination test using $1 \%$ chicken erythrocytes (OIE, 2015). Bacteria-free AF was pooled and virus was titrated by plaque assay as described below.

Madin-Darby canine kidney cells II (MDCKII) and adenocarcinomic human alveolar basal epithelial cells (A549) were obtained from the FLI. Chicken embryo kidney cells (CEK) were prepared from kidneys of 18-day-old SPF ECE (Lohmann Animal Health, Germany) according to Standard procedures.

\section{Plaque Assay}

Titration of viruses was performed in MDCKII by ten-fold serial dilutions. The cells were infected for $1 \mathrm{~h}$, then washed twice with $\mathrm{PBS}$ and overlaid with $3 \mathrm{ml}$ plaque test medium, minimal essential medium (MEM) containing 37\% fetal calf serum (Sigma, Germany) and 1.8\% Bacto-agar (BD, USA) at a 1:1 ratio. Trypsin was added not to the cells because HPAIV can grow in the presence of serum without trypsin. Plates were incubated at $37^{\circ} \mathrm{C}, 5 \% \mathrm{CO}_{2}$ for 3 days and then fixed with formalin containing crystal violet. The number of plaques was counted and the final titers were calculated and expressed as plaque forming unit per $\mathrm{ml}(\mathrm{PFU} / \mathrm{ml})$. For measuring the size of plaques produced by different viruses in MDCKII, Nikon Instruments NIS elements basic research software was used.

TABLE 1 | Viruses isolated or used in this study.

\begin{tabular}{|c|c|c|c|}
\hline H5N1 Viruses & Abbreviation & HA accession number* & Clade \\
\hline \multicolumn{4}{|c|}{ VIRUSES USED IN BIOLOGICAL CHARACTERIZATION } \\
\hline A/chicken/Egypt/083-NLQP/2008 & 2.2.1-A & CY044032 & 2.2 .1 \\
\hline A/chicken/Egypt/0815-NLQP/2008 & 2.2.1-B & GQ184221 & 2.2.1 \\
\hline A/chicken/Egypt/0879-NLQP/2008 & 2.2.1.1 & GQ184238 & 2.2.1.1 \\
\hline A/duck/Egypt/0897-NLQP/2008 & 2.2.1.2-A & JF746738 & $2 \cdot 2 \cdot 1 \cdot 2^{\star \star}$ \\
\hline \multicolumn{4}{|l|}{ VIRUSES USED IN DUCK EXPERIMENT } \\
\hline A/chicken/Egypt/0879-NLQP/2008 & 2.2.1.1 & GQ184238 & 2.2.1.1 \\
\hline A/turkey/Egypt/AR1507/2016 & 2.2.1.2-D & EPI827065 & 2.2.1.2 \\
\hline
\end{tabular}

*GISAID/GenBank accession numbers, ${ }^{* \star}$ Early 2.2.1.2 = 2.2.1/C clade. 


\section{Replication Kinetics}

CEK, MDCKII and A549 cells were infected with 1PFU per 1000 cells in 2-4 independent assays. After $1 \mathrm{~h}$, cells were washed with citrate-buffered saline (CBS) $\mathrm{pH} 3.0$ to inactivate extracellular virions. Then, the cells were washed twice with isotonic PBS, and infection medium, MEM with bovine serum albumin (BSA), was added and incubated for $1,8,24,48$, and $72 \mathrm{~h}$ post-infection (hpi) at $37^{\circ} \mathrm{C}$ and $5 \% \mathrm{CO}_{2}$. Harvested cells and supernatants were stored at $-80^{\circ} \mathrm{C}$ until use. The results were expressed as average and standard deviation of $\mathrm{PFU} / \mathrm{ml}$ of all replicates.

\section{Thermo- and pH Stability}

The titre of indicated viruses used in biological characterization (Table 1) were adjusted to $10^{5}-10^{6} \mathrm{PFU} / \mathrm{ml}$ and aliquots were incubated in duplicates at $4^{\circ} \mathrm{C}$ for $1,2,3$, and 4 months. Also, duplicates were incubated at $56^{\circ} \mathrm{C}$ for $0,1,2,3$, and $4 \mathrm{~h}$ or were incubated with an equal volume with $\mathrm{PBS} \mathrm{pH} 4,5,6$, 7 , or 7.4 at room temperature $\left(20\right.$ to $\left.22^{\circ} \mathrm{C}\right)$ for up-to 7 days followed by neutralization with sodium hydroxide. Aliquots were removed and stored at $-80^{\circ} \mathrm{C}$ until use. The decrease in HA titre and infectivity was investigated using HA test and plaque assay, respectively. The HA test was conducted in duplicate for each replicate. The experiments were repeated twice and the average and standard deviation of each experiment were given.

\section{Receptor Binding Assay}

Affinity to avian $\alpha 2,3$ and human-like $\alpha 2,6$ - sialic acid (SA) receptors was assessed using modified turkey erythrocytes (TRBCs) (Herfst et al., 2012). Briefly, SA was removed from TRBCs by incubation with Vibrio cholerae neuraminidase (Sigma-Aldrich, Germany) in the presence of calcium chloride (Herfst et al., 2012). After washing with PBS, desialylated TRBCs were suspended in PBS containing 1\% BSA. Complete loss of hemagglutination of the TRBCs was confirmed by incubation with control viruses (i.e., PR8 and H4N2). Resialylation was done using $\alpha 2,6-(\mathrm{N})$-sialyltransferase (Takara, Germany) or $\alpha 2,3-(\mathrm{N})$-sialyltransferase (Sigma-Aldrich, Germany) in final concentrations of $1.5 \mathrm{mM}$ Cytidine $5^{\prime}$-monophosphate (CMP)sialic acid (Sigma-Aldrich, Germany). Modified TRBCs were suspended in PBS containing $1 \%$ bovine serum albumin to a final concentration of $0.5 \%$. Resialylation was confirmed by hemagglutination of viruses using human PR8 with high affinity to $\alpha 2,6$-SA and H4N2 with high affinity to avian $\alpha 2,3$ $\mathrm{SA}$ receptors. HA test was done using the modified TRBCs, desialylated RBCs and original turkey RBCs (OIE, 2015). The assay was run in duplicates and repeated twice.

\section{Experimental Infection of Ducks}

The animal experiment in this study was conducted in the biosafety level 3 animal facilities of the FLI following the German Regulations for Animal Welfare after approval by the authorized ethics committee of the State Office of Agriculture, Food Safety, and Fishery in Mecklenburg-Western Pomerania. The experiment was approved by the commissioner for animal welfare at the FLI representing the Institutional Animal Care and Use Committee.
Sixty 4 to 5 -week-old Pekin $(n=30)$ and Muscovy $(n=30)$ ducks were purchased from a commercial, influenza-free breeder flock. Birds were housed for 4 days before virus inoculation. Water and feed were supplied ad-libitum. Blood samples as well as oropharyngeal and cloacal swabs were collected pre-infection. At day of inoculation (day 0), 10 birds per group were inoculated via the oculo-nasal route with $0.2 \mathrm{ml}$ inoculum containing $10^{5}$ PFU/bird of each virus. At day 1 post-inoculation (dpi), 5 sentinel birds were added to each group. Ducks were observed daily for 14 days post-inoculation. Pathogenicity index (PI) based on clinical scoring was done as following: 0 for healthy birds, 1 for birds with one clinical sign (depression, nervous signs, respiratory signs, diarrhea, or facial oedema), 2 for birds that showed more than one clinical sign, and 3 for dead birds. Moribund birds which could not eat or drink were euthanized and scored 3 at the next day. The PI was calculated from the daily mean score of all birds during a 14-day observation period. All survived birds at the end of the experiment were anesthetized by inhalation of isoflurane (CP-Pharma, Germany), and then slaughtered and the blood was collected from the jugular veins.

To determine the level of viral excretion swabs were collected in MEM containing BSA and antibiotics from surviving ducks at $2,4,7,11$, and $14 \mathrm{dpi}$. Also, lung and spleen samples were collected at 3 dpi from three birds killed for histopathology as described below. Viral RNA was extracted from swabs using NucleoSpin 8/96 PCR Clean-up Core Kit (Macherey \& Nagel $\mathrm{GmbH}$ ) and from organs using NucleoMag kit according to the manufacturer instructions in automatic extraction. Realtime reverse-transcription polymerase chain reaction (RT-qPCR) targeting the matrix gene was used (Hoffmann et al., 2016). Standard curves for virus quantification were generated in each RT-qPCR plate using RNA extracted from 10-fold serial dilutions of 2.2.1.1 virus. Ct values of samples were plotted against the standard curves and the results were presented as PFU/ml.

To investigate the distribution of influenza antigens in different tissues, 3 birds per group were euthanized at $3 \mathrm{dpi}$ by isoflurane inhalation and blood withdrawal. Samples were collected from trachea, lung, heart, spleen, liver, pancreas, duodenum, jejunum, cecal tonsils, bursa of Fabricius, thymus, and brains. All samples were fixed in formalin and embedded in paraffin-wax, then subjected to histopathologic and immunohistochemistry (IHC) examination. Primary anti-influenza NP-antibodies and secondary biotinylated goat anti-rabbit IgG1 (Vector) antibodies (1:200) were used to detect $\mathrm{H} 5 \mathrm{~N} 1$ antigens in different tissues (Klopfleisch et al., 2006). The intensity of signals of influenza nucleoprotein was semi-quantified by scoring on a 0 to 4 scale for tissues: $0=$ negative; $1=$ single cells, $2=$ scattered foci, $3=$ numerous foci, $4=$ coalescing foci or diffuse; and on a scale of 0 to 3 for endothelium: $0=$ negative; $1=$ single blood vessel, $2=$ multiple blood vessels, 3 = diffuse, as described previously (Klopfleisch et al., 2006).

Serum samples collected at day 0 and at the end of the experiment from surviving birds were inactivated at $56^{\circ} \mathrm{C}$ for $2 \mathrm{~h}$ and tested by a commercial enzyme linked immunosorbent assay (ELISA) targeting the NP of AIV as recommended by the manufacturer (ID Screen ${ }^{\circledR}$ Influenza A Antibody Competition 
Multi-species, IDvet). The results of ELISA were confirmed using hemagglutination inhibition (HI) test against $8 \mathrm{HAU}$ of the challenge viruses (OIE, 2015).

\section{Statistic Analysis}

For the duck experiment, differences in viral excretion at 2 and $4 \mathrm{dpi}$, respectively, were evaluated using Kruskal-Wallis tests followed by Wilcoxon tests using the Benjamini-Hochberg procedure for multiple testing correction. Clinical scoring was compared across groups based on the mean clinical score per bird during a 14 days observation period in the same manner. In vitro replication kinetics were analyzed by a repeated measures ANOVA with Benjamini-Hochberg-corrected post-hoc tests. All computations in this study were performed in $\mathrm{R}$ version 3.3.1 from the R-project website (http://www.r-project.org) with packages nlme, car, multcomp and MASS (Venables and Ripley, 2002; Hothorn et al., 2008; R Core-Team, 2015; Pinheiro et al., 2017).

\section{RESULTS}

\section{Ambient Temperature Influenced the Prevalence of $A / H 5 N 1$ Outbreaks in Examined Regions in Egypt}

Data on temperature, humidity, and wind speed from 2006 to 2015 were analyzed for overall Egypt and for four selected provinces (Figure 1). In 2006, 185 outbreaks of avian influenza in domestic poultry were reported in Egypt. In the following 2 years, the number of outbreaks decreased to 69 cases in 2008 but increased to over 200 cases in 2009 and 2010. After a decline for the following 3 years, the number of outbreaks peaked at 445 cases in 2014/2015, where Cairo, Minya, and Luxor had the highest number of outbreaks. On the contrary, Alexandria showed a steady decrease in outbreaks from 2006 onwards.

Potential correlations of single climate factors with outbreaks of $\mathrm{A} / \mathrm{H} 5 \mathrm{~N} 1$ in Egypt were analyzed by Spearman's correlation coefficients $(\rho)$. As shown in Table 2, only weak to moderate correlations were observed for overall Egypt and also for each of the governorates. For instances, the decrease in the number of outbreaks in Alexandria correlates with an increase of humidity $(\rho=-0.61)$ and the increase of outbreaks in Minya correlated with an increase of the minimum temperature per winter season $(\rho=0.45)$. However, none of the correlations were statistically significant $(P<0.05)$. Accordingly, the observed variation in A/H5N1 outbreaks could not be attributed to a single climate factor.

Nevertheless, the variation in $\mathrm{A} / \mathrm{H} 5 \mathrm{~N} 1$ outbreaks might have been influenced by a combination of several climate factors. Therefore, five negative binomial regression models, which differed in the choice of explanatory variables (with/without climate factors and with/without regional effects, one model resulted from the variable selection procedure), were constructed for the governorate-level data. All proposed negative binomial regression models showed similar deviances and fit reasonably well to the data according to goodness of fit tests $\left(\chi^{2}\right.$ tests on the deviances) (Table 3). However, likelihood ratio tests
TABLE 2 | Correlation of climatic factors with A/H5N1 outbreaks in poultry in all Egypt and the four selected governorates.

\begin{tabular}{lrrlcr}
\hline & $\begin{array}{c}\text { Temp. } \\
\text { (min) }\end{array}$ & $\begin{array}{c}\text { Temp. } \\
\text { (max) }\end{array}$ & $\begin{array}{l}\text { Temp. } \\
\text { (average) }\end{array}$ & $\begin{array}{c}\text { Humidity } \\
\text { (\%) }\end{array}$ & $\begin{array}{r}\text { Wind } \\
\text { speed }\end{array}$ \\
\hline Entire Egypt & 0.38 & 0.03 & 0.35 & -0.18 & 0.29 \\
Alexandria & -0.03 & -0.03 & 0.17 & -0.61 & 0.39 \\
Cairo & 0.28 & 0.23 & 0.20 & 0.02 & -0.02 \\
Minya & 0.45 & 0.29 & 0.37 & 0.17 & -0.14 \\
Luxor & 0.21 & -0.16 & 0.19 & 0.17 & -0.10 \\
\hline
\end{tabular}

Spearman's correlation coefficient.

None of the reported correlations is statistically significant $(P<0.05)$.

comparing the full model with all other proposed models indicated that incorporation of both regional and climate effects significantly improved model performance. Yet some climate variables may be omitted from the full model as the difference in log-likelihood between our reduced model (resulting from the variable selection procedure) and the full model was not statistically significant. As expected, our reduced model showed the best fit regarding the AIC. It comprised regional effects, maximum temperature and average temperature as explanatory variables. The regression coefficients indicated a significantly increased baseline risk for Minya and Luxor, but not for Cairo, in comparison to Alexandria (Table 3; Supplementary Figure S1). Furthermore, according to this model an increase in maximum temperature (while average temperature remains unchanged) corresponded to a decrease in the number of outbreaks $(\beta=$ -2.38). Conversely, an increase in average temperature (while maximum temperature remains unchanged) corresponded to an increase in the number of outbreaks $(\beta=2.79)$. Both effects were statistically significant (Table 3 ). Thus, an increase in average temperature appears to promote $\mathrm{A} / \mathrm{H} 5 \mathrm{~N} 1$ outbreaks whereas very hot days in winter seasons presumably counteract this trend.

This finding could be validated using the nation-level data for all Egypt. Based on this data, a negative binomial regression model using only average temperature and maximum temperature per winter season as explanatory variables indicated that an increase in average temperature increased the risk of an outbreak $(\beta=1.79)$ while an increase in maximum temperature decreased the risk of an outbreak $(\beta=-1.50)$. Again, both effects were statistically significant (Supplementary Table S1, Supplementary Figure S2). Hence, even though this model represents a strong simplification of the actual outbreak scenario, it reveals a potential connection between ambient temperature and $\mathrm{A} / \mathrm{H} 5 \mathrm{~N} 1$ outbreaks and confirms the findings of the best fitting-model for the governorate-level data.

Taken together, ambient temperature is a potential driving climate factor for $\mathrm{A} / \mathrm{H} 5 \mathrm{~N} 1$ outbreaks in Egypt. Our results imply that average temperature of the respective winter season affected the number of outbreaks. Since all models simplify the complexity of the epidemiology of A/H5N1 in Egypt, none of them fully explains the observed variation in A/H5N1 outbreaks (Supplementary Figure S1, Supplementary Figure S2). 
TABLE 3 | Negative binomial regression models for explaining the observed number of A/H5N1 outbreaks in winter season (d.f., degrees of freedom).

\begin{tabular}{|c|c|c|c|c|c|c|c|c|c|}
\hline & \multicolumn{4}{|c|}{ Model parameters } & \multicolumn{5}{|c|}{ Model performance } \\
\hline & & $\beta$ & SE & $\begin{array}{c}P \text {-value } \\
\text { (Wald test) }\end{array}$ & Deviance & $\begin{array}{l}P \text {-value ( } \chi^{2} \text { test, } \\
\text { goodness of fit) }\end{array}$ & AIC & $\begin{array}{c}2 \times \text { log- } \\
\text { likelihood }\end{array}$ & $\begin{array}{l}P \text {-value (Likelihood } \\
\text { ratio test to full model) }\end{array}$ \\
\hline \multirow[t]{8}{*}{ Full model } & Cairo & -1.45 & 1.25 & 0.24 & 39.78 & 0.05 & 206.16 & -186.16 & - \\
\hline & Minya & 6.38 & 3.00 & $\underline{0.03}$ & (27 d.f.) & & & & \\
\hline & Luxor & 4.68 & 4.10 & 0.25 & & & & & \\
\hline & Temp (min) & 0.46 & 1.40 & 0.75 & & & & & \\
\hline & Temp (max) & -2.02 & 1.08 & 0.06 & & & & & \\
\hline & Temp (average) & 1.92 & 2.30 & 0.40 & & & & & \\
\hline & Humidity & -0.08 & 0.08 & 0.33 & & & & & \\
\hline & Wind & -0.09 & 0.17 & 0.59 & & & & & \\
\hline \multirow[t]{5}{*}{ Reduced model } & Cairo & -0.32 & 0.60 & 0.59 & 39.82 & 0.11 & 201.00 & -187.00 & 0.84 \\
\hline & Minya & 7.53 & 2.27 & $\leq 0.01$ & (30 d.f.) & & & & \\
\hline & Luxor & 6.64 & 2.53 & $\leq 0.01$ & & & & & \\
\hline & Temp (max) & -2.38 & 0.79 & $\leq 0.01$ & & & & & \\
\hline & Temp (average) & 2.79 & 0.88 & $\leq 0.01$ & & & & & \\
\hline \multirow[t]{5}{*}{ Climate factors only } & Temp (min) & 0.39 & 0.98 & 0.69 & 39.41 & 0.12 & 211.14 & -197.14 & 0.01 \\
\hline & Temp (max) & 0.12 & 0.74 & 0.87 & (30 d.f.) & & & & \\
\hline & Temp (average) & -0.51 & 1.69 & 0.76 & & & & & \\
\hline & Humidity & 0.09 & 0.04 & 0.03 & & & & & \\
\hline & Wind & -0.29 & 0.16 & 0.06 & & & & & \\
\hline \multirow[t]{3}{*}{ Regional effects only } & Cairo & -0.65 & 0.65 & 0.31 & 39.74 & 0.16 & 208.28 & -198.28 & 0.03 \\
\hline & Minya & 0.86 & 0.63 & 0.17 & (32 d.f.) & & & & \\
\hline & Luxor & -0.25 & 0.64 & 0.70 & & & & & \\
\hline \multirow[t]{2}{*}{ Null model } & & & & & 39.92 & 0.26 & 208.26 & -204.26 & 0.02 \\
\hline & & & & & (35 d.f.) & & & & \\
\hline
\end{tabular}

Underlined values indicate significant difference $(P<0.05)$.

\section{Viruses in Clade 2.2.1.1 and Recent 2.2.1.2 Exhibit Increased Stability at Low and High Temperature}

At $4^{\circ} \mathrm{C}$, all viruses survived for at least 4 months. The 2.2.1.1 virus and 2.2.1.2-B were more stable and showed the highest titres compared to the other viruses used in this study (Figure 2A). After 4 months, 2.2.1.1 virus and 2.2.1.2-B had 10- to 100-fold higher titres than the other viruses (Figure 2A). Likewise, at $56^{\circ} \mathrm{C}$ all viruses were relatively stable for $2 \mathrm{~h}$. The recent 2.2.1.2 and 2.2.1.1 viruses were more stable than other viruses after $3 \mathrm{~h}$. The 2.2.1.1 virus and 2.2.1.2-B were not totally inactivated even after $4 \mathrm{~h}$ (Figure 2B). Moreover, all viruses were stable at different $\mathrm{pH}$ for 7 days. 2.2.1.2-B showed a $\sim 10$-fold decreased titre at lower $\mathrm{pH}$ (Figure 2C).

\section{Antigenic Drift 2.2.1.1 Virus Replicated at Lower Levels in Human Lung Cells Compared to the Other Viruses}

All Egyptian viruses reacted at similar levels using unmodified TRBCs (HA titre 256) as well as against $\alpha 2,3$-SA carrying RBCs (HA titre 64 to 128). The viruses varied in binding to $\alpha 2,6-\mathrm{SA}$ RBCs although at 2- to 16 -fold lower efficiency than to avian $\alpha 2,3$-SA receptors. The 2.2.1.1 and 2.2.1-B reacted 2- to 8-fold less than other viruses. 2.2.1.2-D bound to $\alpha 2,6$-SA receptors 4-fold higher than 2.2.1.1 (Figure 2D). PR8 bound at similar levels to unmodified TRBCs and $\alpha 2,6-\mathrm{SA}$ carrying RBCs and did not bind to the avian $\alpha 2,3-\mathrm{SA}$ receptors. Conversely, H4N2 did not bind to $\alpha 2,6-S A-T R B C s$ (data not shown). All viruses reached the maximum titer at $24 \mathrm{hpi}$ in CEK (Figure 3A) and MDCKII (Figure 3B). Interestingly, in A549, 2.2.1.1 replicated at significantly lower titre than 2.2.1.2-C at 8, 24, 48, and 72 hpi and lower than 2.2.1-A at $24 \mathrm{hpi}$ (Figure 3C). While 2.2.1-A produced the largest plaques, 2.2.1-B and 2.2.1.2-B produced the smallest plaques. Plaque size induced by the 2.2.1.1 virus was significantly larger than the recent 2.2.1.2 viruses (2.2.1.2-B and 2.2.1.2-C) (Figure 3D).

\section{Pekin Ducks Are More Resistant Than Muscovy Ducks Toward Infection With Different Egyptian H5N1 Viruses}

Pekin ducks (groups 1 and 2) were more resistant than Muscovy ducks (groups 3 and 4) after inoculation with the Egyptian $\mathrm{H} 5 \mathrm{~N} 1$ viruses of clade 2.2.1.1 and 2.2.1.2 (Figure 4). A total of $1 / 7,0 / 7,6 / 7$, and $6 / 7$ inoculated birds died in groups 1 to 4 , 

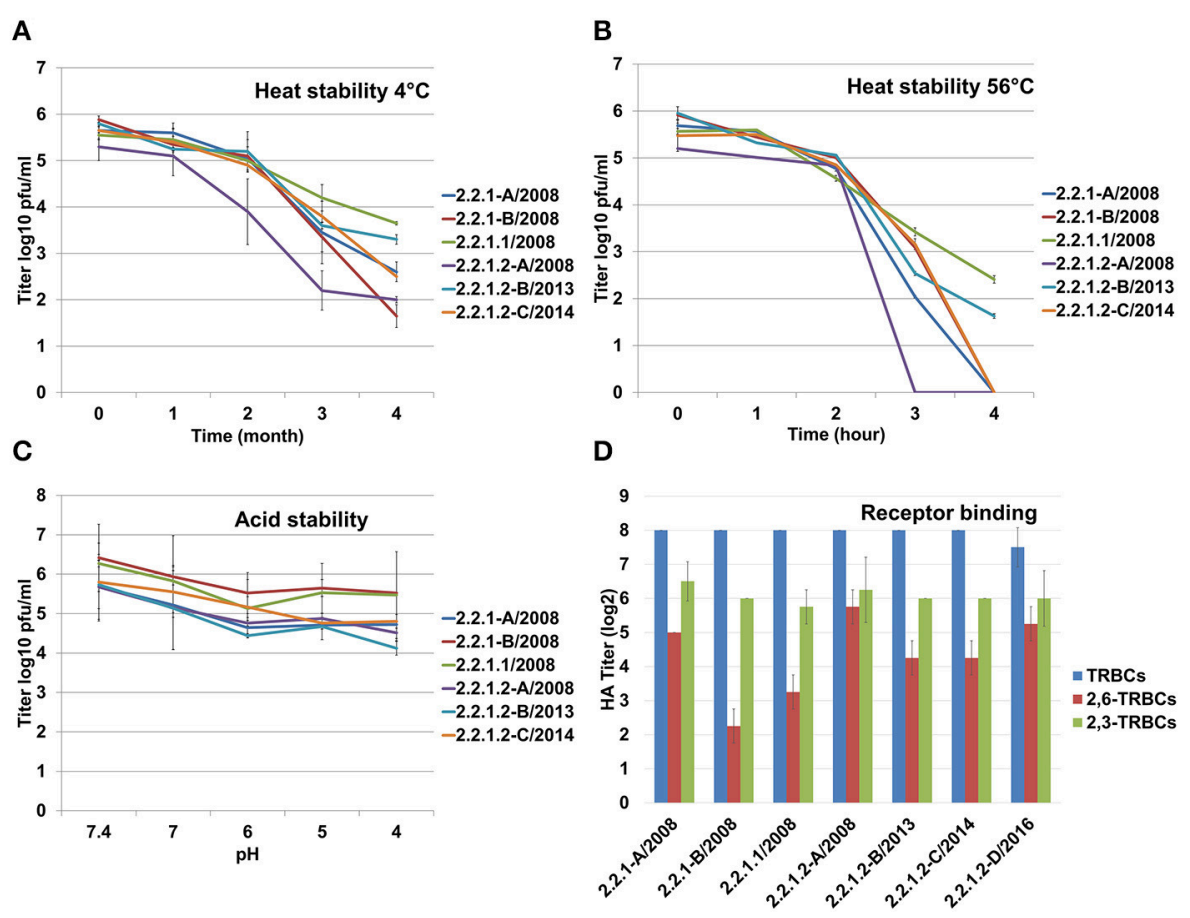

FIGURE 2 | Stability of the Egyptian H5N1 viruses at different temperatures and pHs. Heat stability at $4^{\circ} \mathrm{C}$ (A) or $56^{\circ} \mathrm{C}$ (B), and acid stability (C). (D) Receptor binding affinity was tested against turkey RBCs (TRBCs) and modified TRBCs carrying avian $\alpha 2,3$ and human-like $\alpha 2,6$ - sialic acid. All experiments were conducted in duplicates, heat stability at $56^{\circ} \mathrm{C}$ and acid stability was assessed in two independent experiments. Shown are the average and standard deviations of all experiments. Titration of viruses was carried out in MDCKIl cells.
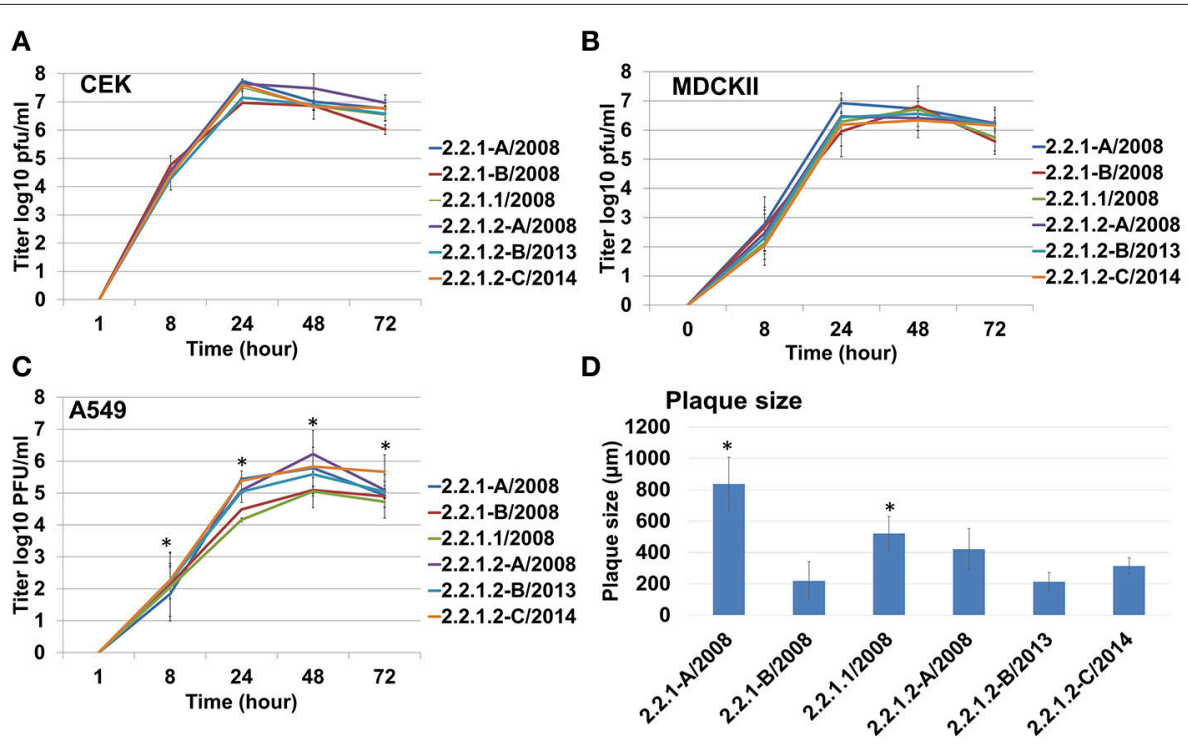

FIGURE 3 | Replication and cell-to-cell spread of different Egyptian-origin H5N1 viruses. Replication of different viruses in chicken embryo kidney (CEK) cells (A), Madin-Darby canine kidney type II (MDCKII) cells (B), human adenocarcinoma lung cells (A549) (C). All experiments were repeated 2-4 times. Cell-to-cell spread was analyzed by measuring plaque size induced by different viruses in MDCKIll cells (D). ${ }^{\star} P<0.05$.

respectively. None of contact Pekin ducks died, whereas 5/5 and $4 / 5$ contact Muscovy ducks died in groups 3 and 4 , respectively (Figure 4). In group 1, all inoculated Pekin ducks except bird number 1 and 5 were clinically healthy up to the end of the experiment. Bird number 1 showed depression beginning at 4 dpi, whereas bird number 5 showed severe nervous signs and 

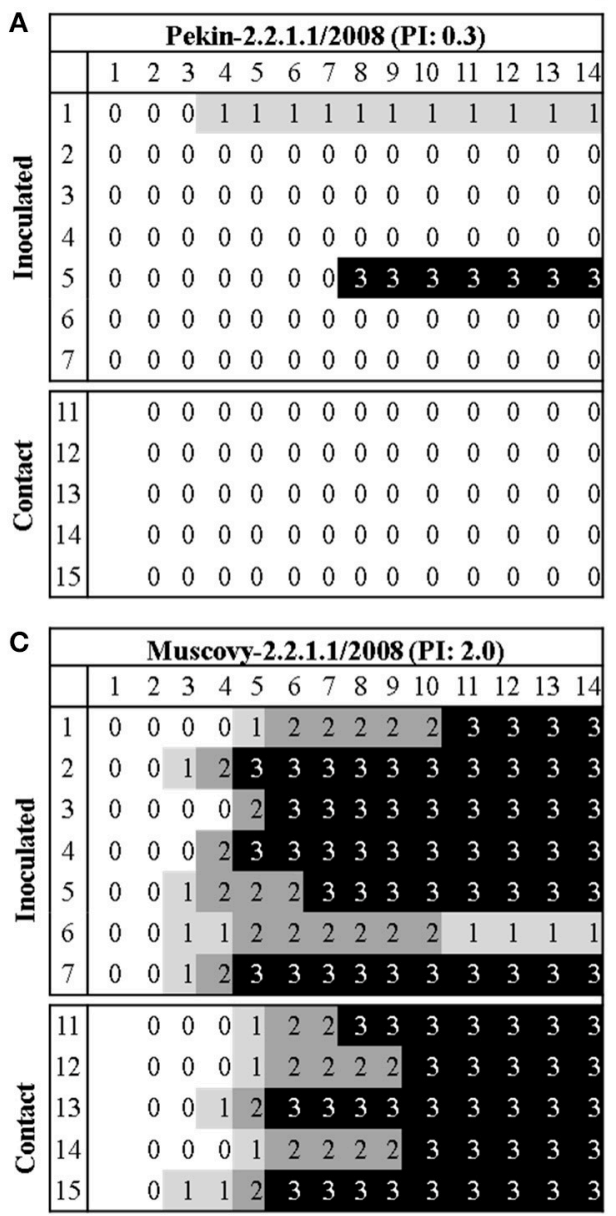

Days post infection (dpi)
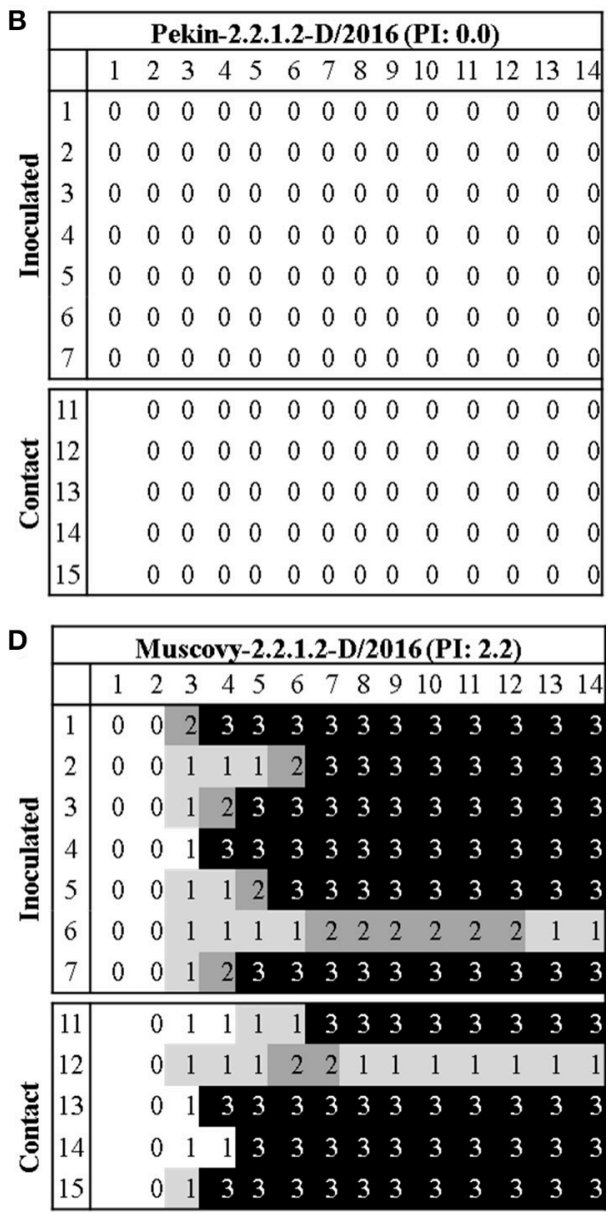

FIGURE 4 | Morbidity and mortality in Pekin and Muscovy ducks after inoculation with two different A/H5N1 of clades 2.2.1.1 and 2.2.1.2. Clinical scoring after oculonasal infection of 4-5 weeks old Pekin (A,B) or Muscovy (C,D) ducks with H5N1 viruses belonging to clades 2.2.1.1 (A,C) or 2.2.1.2 (B,D). At 1 day post inoculation, five naïve ducks were added to assess virus transmissibility. All birds were observed for up to 14 days. Ducks without clinical symptoms were scored "0". The score "1" was applied to ducks showed one of the following clinical signs: depression, ruffled feathers, diarrhea, discharges, torticollis, opisthotonus, or rolling. These ducks were categorized as ill. Severely ill ducks showed two or more clinical signs were scored "2," whereas dead ducks were scored "3." Birds which could not eat or drink were euthanized and scored 3 at the next day of observation. The pathogenicity index (PI) for each group was expressed as the mean sum of the daily arithmetic mean values divided by 14; the number of observation days.

therefore was killed at $7 \mathrm{dpi}$ and scored dead at day 8 postinoculation (Figure 4A). In group 2, all inoculated Pekin ducks remained healthy. Likewise, all contact ducks in both groups were apparently healthy (Figure 4B). On the contrary to Pekin ducks, the majority of Muscovy ducks inoculated with 2.2.1.1 (group 3) or 2.2.1.2 (group 4) died by day 11 post-inoculation. Clinical signs started at $3 \mathrm{dpi}$ with no significant difference in groups 3 and $4(p=0.29)$. In group 3, 6 out of 7 Muscovy birds died with a mean death time of 6.5 days and a PI of 2. All contact birds in this group died by day 10 post-inoculation after showing mild to severe clinical signs. Clinical signs started with depression and progressed quickly to become moderate to severe (Figure 4C). In group 4, 6 out of 7 inoculated birds died by day 7 post-inoculation with a mean death time of 5.2 days and a PI of 2.2. The onset of death in group 4 started 1 day earlier than in group 3. Four out of 5 contact birds died in group 4 by day 7 . The onset of death started at $4 \mathrm{dpi}, 2$ days earlier than in group 3 (Figure 4D). One inoculated bird each from groups 3 and 4 , and 1 contact bird from group 4 survived. However, they remained sick during the duration of the experiment showing torticollis but were able to obtain food and water.

At $2 \mathrm{dpi}$, the majority of ducks in group 1 and all ducks in groups 2, 3, and 4 excreted viruses confirmed by oral and cloacal swabs (Figure 5, Supplementary Table S2). Muscovy ducks excreted significantly higher amounts of the viruses than Pekin ducks. Also, the level of virus excretion in ducks inoculated with the 2.2.1.2 virus at 2 dpi was significantly higher than those infected by 2.2.1.1 virus. At day 4 , the majority of Pekin ducks excreted viruses although at lower levels than Muscovy ducks. All Muscovy ducks excreted viruses orally and/or cloacally. Muscovy 


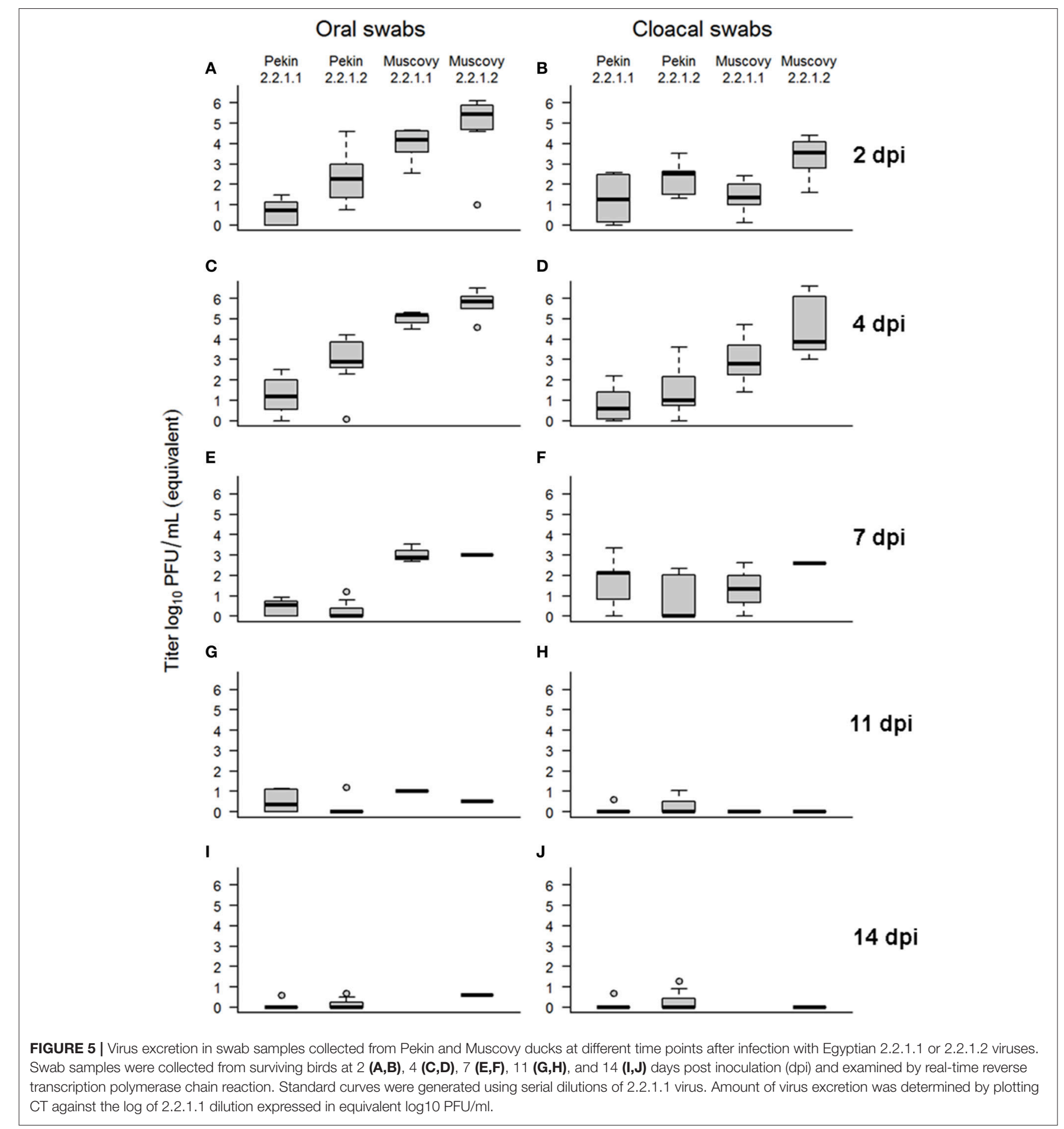

ducks infected with 2.2.1.2 had a higher amount of virus in cloacal swabs than those infected with 2.2.1.1 $(p=0.0078)$. At 11 and 14 dpi some surviving ducks secreted viruses orally and/or cloacally, although at low levels (Supplementary Table S2, Figure 5).

Distribution of influenza antigen in different organs was analyzed by IHC (Figure 6; Supplementary Table S3), and in lung and spleen samples using RT-qPCR (Supplementary Figure S3). Breed has a major effect on distribution of $\mathrm{A} / \mathrm{H} 5 \mathrm{~N} 1$ in different organs. No NP-antigen was detected in Pekin ducks at 3 dpi using IHC, however, using RT-qPCR, 2.2.1.1 and 2.2.1.2 viruses were detected in the lungs, but not spleen, of Pekin ducks (Supplementary Figure S3). In contrast, in primary inoculated Muscovy ducks NP antigen was detected in neuroglial 


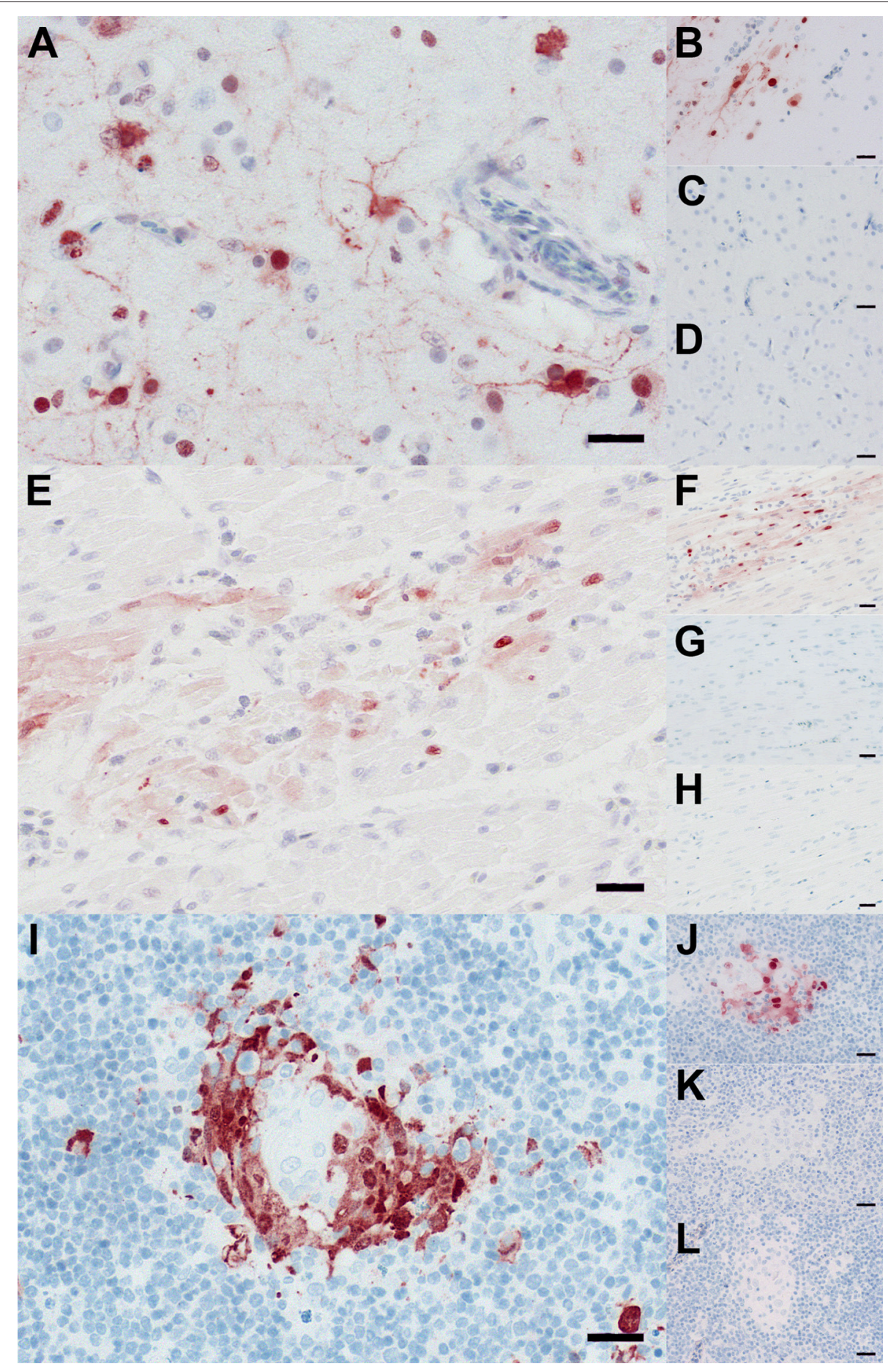

FIGURE 6 | Distribution of A/H5N1 in tissues of Pekin and Muscovy ducks. Immunohistochemistry revealed influenza A-virus nucleoprotein-antigen in neuroglial cells within the brain (A,B), cardiomyocytes within the heart (E,F), and thymocytes within the thymus (I,J) of Muscovy ducks (A,B,E,F,I,J). In contrast, influenza A-virus

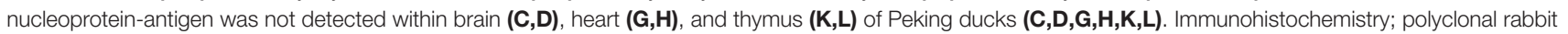
anti- influenza A FPV/Rostock/34-virus-nucleoprotein antiserum; avidin-biotin-peroxidase-complex method; 3-amino-9-ethyl-carbazol chromogen (red-brown); hematoxylin counterstain (blue); Bars $=20 \mu \mathrm{m}$. More immunostaining slides are available upon request.

cells, cardiomyocytes, and thymocytes (Figure 6) as well as in a contact bird (data not shown). Variation in the distribution of 2.2.1.1 and 2.2.1.2 $\mathrm{A} / \mathrm{H} 5 \mathrm{~N} 1$ antigen in Muscovy ducks was also observed. In Group 3, the antigen was not detected in the tracheal epithelium, liver, and kidneys; conversely all three ducks in group 4 had remarkable infiltration in these organs. 
In the gastrointestinal tract (duodenum, jejunum, cecal tonsils, proventriculus, and gizzard), the virus was detected only in birds of group 4, particularly in the neurons in peripheral ganglia. In Group 3, infected areas found in the lung and brain were less frequent compared to birds in group 4 . In the lung of animals from group 4, virus antigen was detected in the upper and lower respiratory tract, while birds in group 3 showed viral antigen only in the bronchial epithelium. Viral antigen was not detected in endothelial cells in any organ or the circulatory system in Pekin or Muscovy ducks. Using RTqPCR, viral RNA was also detected in the lungs and spleen of Muscovy ducks in groups 3 and 4 (Supplementary Figure S3).

Serum samples collected before infection were negative for AIV NP antibodies using ELISA. At the end of the experiment, sera from group $1(n=11)$, group $2(n=12)$, group 3 $(n=1)$, and group $4(n=2)$ were examined by NP-ELISA and $\mathrm{HI}$ test against homologous and heterologous antigens. Using ELISA, all sera post-infection were positive. Using HI test against 2.2.1.2-D antigen, all samples in groups 2 and 4 were positive ( $\mathrm{HI}$ titer $\geq 8$ ) with a mean titer of between 3.8 and $5 \log _{2}$, in inoculated birds and 3.2 and $5 \log _{2}$ in contact birds, respectively. Surviving birds in Group 1 and Group 3 were tested negative (HI titer $<8$ ). Using 2.2.1.1 antigen, the sera of inoculated birds in groups 1 and 3 reacted at similar levels with a mean titer 4.7 and $6 \log _{2}$, respectively, and no cross reaction with the 2.2.1.2-D antigen was obtained.

\section{DISCUSSION}

Since the introduction of 2.2.1 clade of A/H5N1 into poultry in Egypt in 2006, the virus established an endemic status and spilled over to humans making Egypt the country with the longest endemic status outside Asia and with the highest number of human infections. Understanding the factors driving the evolution and persistence of the Egyptian A/H5N1 may enable prediction and control of future outbreaks.

In this study, climatic factors during moderate to relatively cold months (October to March) where the number of outbreaks (i) is high and (ii) allows statistical analysis were collected. In summer, the prevalence of outbreaks is very low (Arafa A. et al., 2012; Arafa A. S. et al., 2012; El-Zoghby et al., 2013) and therefore statistical analysis will be misleading. Statistical analysis of selected climatic factors in this study indicated that ambient temperature influenced the prevalence of A/H5N1 outbreaks in Egypt from 2006 to 2015. Also, the thermostability of viruses from clade 2.2.1.1 and recent clade 2.2.1.2 at $56^{\circ} \mathrm{C}$ degrees is remarkable. Thus, we assume that the ability of some $\mathrm{A} / \mathrm{H} 5 \mathrm{~N} 1$ viruses to survive at elevated temperatures (i.e., in summer season when temperature is over $40^{\circ} \mathrm{C}$ ) is an important factor for the persistence and spread of $\mathrm{H} 5 \mathrm{~N} 1$ in Egypt. In a previous study, clade 2.2.1.2 virus was isolated from domestic ducks in mid-summer in Egypt (Hassan et al., 2013). Two major waves of the A/H5N1 in Egypt were reported due to the emergence of clade 2.2.1.1 virus in vaccinated poultry in 2008-2010 and clade 2.2.1.2 virus from October 2014 to March 2015. Viruses isolated from the two waves (2.2.1.1 and 2.2.1.2-B/2.2.1.2-C, respectively) exhibited increased thermal stability than the other viruses, which may be advantageous for virus persistence in harsh environment and spread when the average temperature is moderate (i.e., in winter months). Our results are partially in accordance with the analysis conducted by Murray and Morse (2011) who found that the incidence of $\mathrm{A} / \mathrm{H} 5 \mathrm{~N} 1$ infections in humans in Egypt in 2006-2008 was strongly associated with moderate temperature and humidity. The current study does not explain the disappearance of clade 2.2.1.1 which was probably due to the extensive vaccination using local field-strains, competition with co-circulating $\mathrm{H} 9 \mathrm{~N} 2$ viruses and/or other unknown reasons (Abdelwhab et al., 2016; Hassan et al., 2016; Naguib et al., 2017). Moreover, climatic factors alone did not explain the high prevalence of HPAIV in domestic poultry in 2014/2015. Williams et al. (2011) suggested that anthropogenic factors (human population density, movement, etc.) were important for the spread of A/H5N1 in the Middle East and Northeastern Africa (Williams and Peterson, 2009). Likewise, increased incidence of $\mathrm{A} / \mathrm{H} 5 \mathrm{~N} 1$ outbreaks in the commercial farms in Egypt was most strongly correlated with road network distances (Young et al., 2017).

All viruses replicated well and at similar levels in avian cell culture and had binding affinity to both avian and humanlike receptors, meanwhile cell-to-cell spread was mostly virusspecific. An interesting observation is that the virus in clade 2.2.1.1, which is highly adapted to (vaccinated) chickens, replicated at lower levels in human lung cells than humanlike viruses in clade 2.2.1.2. Mutations in clade 2.2.1.2 viruses increased replication in human cells while maintaining the ability for replication in avian cells (Watanabe et al., 2011b). Although this topic should be further investigated using a broader panel of clade 2.2.1.1 viruses, it has been postulated that the adaptation of $\mathrm{A} / \mathrm{H} 5 \mathrm{~N} 1$ to terrestrial poultry may prevent the evolution of human-adapted viruses (Long et al., 2015). This may partially explain the lower prevalence of clade 2.2.1.1 viruses in humans compared to viruses in clade 2.2.1.2.

Ducks exhibit mild or no clinical signs after infection with $\mathrm{A} / \mathrm{H} 5 \mathrm{~N} 1$ and, therefore, play an important role in the genesis and silent transmission of highly pathogenic viruses to susceptible gallinaceous poultry and probably to humans (Fan et al., 2014; Lee et al., 2014). However, the pathogenicity of H5N1 viruses in ducks may vary according to the duck species, age of ducks, virus strain and inoculation route (Pantin-Jackwood and Swayne, 2009; Szeredi et al., 2010; Cagle et al., 2011; Pantin-Jackwood et al., 2012, 2013; Yuan et al., 2014). In the recent 2014/2015 upsurge in poultry and humans in Egypt, ducks were speculated to be a major source for infection (Arafa et al., 2015). In this study, Muscovy ducks proved to be more sensitive than Pekin ducks which is in accordance with previous studies (Guionie et al., 2010; Cagle et al., 2011). Nearly all inoculated and incontact Muscovy ducks died after infection with human-like clade 2.2.1.2 virus. Conversely, none of the Pekin ducks showed clinical signs or mortality, while producing antibodies and 
excreting a considerable amount of virus from the respiratory and digestive tract for up to $14 \mathrm{dpi}$. Viral RNA was detected in the lungs at $3 \mathrm{dpi}$. The virus was also transmitted to sentinel Pekin ducks without affecting health as shown by virus excretion in swabs and seroconversion. Previously, two Egyptian viruses from 2007 and 2008 from clade 2.2.1 and early clade 2.2.1.1 killed all 2-week-old Muscovy ducks, while 2008-virus killed all 2-week-old Pekin ducks and 2007-virus killed only 10 to $30 \%$ depending on the route of inoculation (Pantin-Jackwood et al., 2013). Furthermore, all Pekin ducks infected with Turkish A/H5N1 of clade 2.2 at 8 -weeks-old died, while 12-week-old Pekin ducks survived the challenge without significant impact on the amount of virus excreted in both groups (Londt et al., 2008, 2010). Pekin and Muscovy ducks challenged intranasally with a clade 2.3.4 A/H5N1 died, after developing neurological signs, within 3.6 and 3.1 days, respectively (Cagle et al., 2011). Variable pathogenicity in domestic ducks may be due to variation in the immune response between the two breeds (Cagle et al., 2011). It is worth mentioning that virus excretion from "silently" infected ducks in this study is in accordance with intermittent excretion of Chinese A/H5N1 from clinically healthy ducks for up to $17 \mathrm{dpi}$ (Hulse-Post et al., 2005). Together, the silent infection of Pekin ducks particularly with human-like clade 2.2.1.2 virus poses public health hazards and intervention strategies (e.g., targeted surveillance in Pekin ducks, segregation of Pekin ducks from backyards, etc.) should be considered.

\section{Limitations of the Study}

Some limitations for the current study should be considered: statistical analysis was conducted for a limited number of regions only, using national surveillance data (i.e., reported outbreaks) and a limited number of factors analyzed herein. Our model reveals an association between temperature and spread of A/H5N1. However, other factors can not be excluded. Moreover, we collected data for the outbreaks from official reports for national surveillance conducted by the ministry of agriculture in cooperation with the FAO. However, these numbers likely do not represent all cases observed in the field. Underreporting of outbreaks in Egypt is not uncommon due to lack of compensation for culling of infected flocks, false information on protection of poultry by vaccination, and masking infection (silent infection) due to partial protection induced by the vaccines (Vergne et al., 2012). Also, although governorates in this study are well known for their highdensity poultry population, we did not find accurate estimates for annual poultry density in these four regions which may affect the number of outbreaks. Importantly, climatic weather for governorates in the Nile delta were not fully available. Lastly, we analyzed only a limited number of factors, while other potential important parameters such as elevation (Loth et al., 2011), chicken density (Pfeiffer et al., 2007), species of birds and density of human population (Gilbert et al., 2008b), and movement of birds, particularly for marketing or hatcheries to rearing areas should be included in future models. Likewise, the impact of seasonal variation on movement or migration of feral or wild birds should be also considered. Biological fitness was assessed using representative viruses from each clade; however, more viruses particularly from clade 2.2.1.1 should be analyzed in the future. Clinical outcome in inoculated ducks with $\mathrm{A} / \mathrm{H} 5 \mathrm{~N} 1$ may be affected by viral doses and ages of ducks (Londt et al., 2010; Pantin-Jackwood et al., 2012) which should be considered in the future. In summary, our study sets a baseline on the importance of several parameters in shaping the epidemiological situation of $\mathrm{A} / \mathrm{H} 5 \mathrm{~N} 1$ infection in poultry and humans in Egypt.

\section{AUTHOR CONTRIBUTIONS}

EA, TM, JV, and $\mathrm{HH}$ conceived and designed the study. AS, DS, and EA conducted the animal experiment. EK, $\mathrm{HE}$, and EA collected data and conducted the climatic factors analysis. $\mathrm{MH}, \mathrm{AA}, \mathrm{WH}$, and $\mathrm{HA}$ provided the official data on the outbreaks in Egypt and/or viruses used in this study. RU conducted the histopathological analysis. EK and EA conducted the statistical analysis. AS, DS, MG, and EA conducted the in-vitro characterization. EA wrote the manuscript. All authors read and approved the final manuscript.

\section{FUNDING}

AS is supported by a doctoral scholarship funded by the Egyptian Ministry of Higher Education, an internship by the Freie Universität Berlin and the FLI. EA was supported by a grant from the Deutsche Forschungsgemeinschaft (DFG; AB 567/1-1). We thank IFT Corporation, Cairo, Egypt, for partially financing the present work. The funders had no role in study design, data collection and analysis, decision to publish, or preparation of the manuscript.

\section{ACKNOWLEDGMENTS}

The authors are grateful to Dajana Helke, Nadine Bock, and Diana Wessler for laboratory technical assistance, to Timm C. Harder for providing the viruses, to Heinz-Günter Strebelow for his assistance in sequencing, to Bärbel Hammerschmidt, Felix Winter, Frank Klipp, Matthias Jahn, Doreen Fiedler, Bärbel Berger, Christian Loth, and Ralf Henkel for their support in the animal experiments and to Silvia Schuparis for histological preparations.

\section{SUPPLEMENTARY MATERIAL}

The Supplementary Material for this article can be found online at: https://www.frontiersin.org/articles/10.3389/fmicb. 2018.00528/full\#supplementary-material 


\section{REFERENCES}

Abdel-Moneim, A. S., Afifi, M. A., and El-Kady, M. F. (2011). Genetic drift evolution under vaccination pressure among H5N1 Egyptian isolates. Virol. J. 8:283. doi: $10.1186 / 1743-422 \mathrm{X}-8-283$

Abdelwhab, E. M., Grund, C., Aly, M. M., Beer, M., Harder, T. C., and Hafez, H. M. (2011). Multiple dose vaccination with heterologous $\mathrm{H} 5 \mathrm{~N} 2$ vaccine: immune response and protection against variant clade 2.2.1 highly pathogenic avian influenza H5N1 in broiler breeder chickens. Vaccine 29, 6219-6225. doi: 10.1016/j.vaccine.2011.06.090

Abdelwhab, E. M., Hassan, M. K., Abdel-Moneim, A. S., Naguib, M. M., Mostafa, A., Hussein, I. T., et al. (2016). Introduction and enzootic of A/H5N1 in Egypt: virus evolution, pathogenicity and vaccine efficacy ten years on. Infect. Genet. Evol. 40, 80-90. doi: 10.1016/j.meegid.2016.02.023

Arafa, A. S., Hagag, N. M., Yehia, N., Zanaty, A. M., Naguib, M. M., and Nasef, S. A. (2012). Effect of cocirculation of highly pathogenic avian influenza H5N1 subtype with low pathogenic H9N2 subtype on the spread of infections. Avian Dis. 56, 849-857. doi: 10.1637/10152-040812-Reg.1

Arafa, A. S., Naguib, M. M., Luttermann, C., Selim, A. A., Kilany, W. H., Hagag, N., et al. (2015). Emergence of a novel cluster of influenza A(H5N1) virus clade 2.2.1.2 with putative human health impact in Egypt, 2014/15. Euro Surveill. 20, 2-8. doi: 10.2807/1560-7917.ES2015.20.13.21085

Arafa, A., Suarez, D., Kholosy, S. G., Hassan, M. K., Nasef, S., Selim, A., et al. (2012). Evolution of highly pathogenic avian influenza H5N1 viruses in Egypt indicating progressive adaptation. Arch. Virol. 157, 1931-1947. doi: $10.1007 /$ s00705-012-1385-9

Cagle, C., To, T. L., Nguyen, T., Wasilenko, J., Adams, S. C., Cardona, C. J., et al. (2011). Pekin and Muscovy ducks respond differently to vaccination with a H5N1 highly pathogenic avian influenza (HPAI) commercial inactivated vaccine. Vaccine 29, 6549-6557. doi: 10.1016/j.vaccine.2011.07.004

Cattoli, G., Fusaro, A., Monne, I., Coven, F., Joannis, T., El-Hamid, H. S., et al. (2011). Evidence for differing evolutionary dynamics of A/H5N1 viruses among countries applying or not applying avian influenza vaccination in poultry. Vaccine 29, 9368-9375. doi: 10.1016/j.vaccine.2011.09.127

Chen, H., Deng, G., Li, Z., Tian, G., Li, Y., Jiao, P., et al. (2004). The evolution of H5N1 influenza viruses in ducks in southern China. Proc. Natl. Acad. Sci. U.S.A. 101, 10452-10457. doi: 10.1073/pnas.0403212101

Dugas, A. F., Jalalpour, M., Gel, Y., Levin, S., Torcaso, F., Igusa, T., et al. (2013). Influenza forecasting with Google Flu Trends. PLoS ONE 8:e56176. doi: 10.1371/journal.pone.0056176

El-Shesheny, R., Bagato, O., Kandeil, A., Mostafa, A., Mahmoud, S. H., Hassanneen, H. M., et al. (2016). Re-emergence of amantadine-resistant variants among highly pathogenic avian influenza H5N1 viruses in Egypt. Infect. Genet. Evol. 46, 102-109. doi: 10.1016/j.meegid.2016.10.022

El-Shesheny, R., Mostafa, A., Kandeil, A., Mahmoud, S. H., Bagato, O., Naguib, A., et al. (2017). Biological characterization of highly pathogenic avian influenza H5N1 viruses that infected humans in Egypt in 2014-2015. Arch. Virol. 162, 687-700. doi: 10.1007/s00705-016-3137-8

El-Zoghby, E. F., Aly, M. M., Nasef, S. A., Hassan, M. K., Arafa, A. S., Selim, A. A., et al. (2013). Surveillance on A/H5N1 virus in domestic poultry and wild birds in Egypt. Virol. J. 10:203. doi: 10.1186/1743-422X-10-203

Fan, S., Zhou, L., Wu, D., Gao, X., Pei, E., Wang, T., et al. (2014). A novel highly pathogenic H5N8 avian influenza virus isolated from a wild duck in China. Influenza Other Respir. Viruses 8, 646-653. doi: 10.1111/irv.12289

Ferenczi, M., Beckmann, C., Warner, S., Loyn, R., O’Riley, K., Wang, X., et al. (2016). Avian influenza infection dynamics under variable climatic conditions, viral prevalence is rainfall driven in waterfowl from temperate, south-east Australia. Vet. Res. 47:23. doi: 10.1186/s13567-016-0308-2

Gilbert, M., Chaitaweesub, P., Parakamawongsa, T., Premashthira, S., Tiensin, T., Kalpravidh, W., et al. (2006). Free-grazing ducks and highly pathogenic avian influenza, Thailand. Emerg. Infect. Dis. 12, 227-234. doi: 10.3201/eid1202.050640

Gilbert, M., Slingenbergh, J., and Xiao, X. (2008a). Climate change and avian influenza. Rev. Off. Int. Epizoot. 27, 459-466. doi: 10.20506/rst.27.2.1821

Gilbert, M., Xiao, X., Pfeiffer, D. U., Epprecht, M., Boles, S., Czarnecki, C., et al. (2008b). Mapping H5N1 highly pathogenic avian influenza risk in Southeast Asia. Proc. Natl. Acad. Sci. U.S.A. 105, 4769-4774. doi: $10.1073 /$ pnas. 0710581105
Grund, C., Abdelwhab el, S. M., Arafa, A. S., Ziller, M., Hassan, M. K., Aly, M. M., et al. (2011). Highly pathogenic avian influenza virus H5N1 from Egypt escapes vaccine-induced immunity but confers clinical protection against a heterologous clade 2.2.1 Egyptian isolate. Vaccine 29, 5567-5573. doi: 10.1016/j.vaccine.2011.01.006

Guionie, O., Guillou-Cloarec, C., Courtois, D., Bougeard, B. S., Amelot, M., and Jestin, V. (2010). Experimental infection of Muscovy ducks with highly pathogenic avian influenza virus (H5N1) belonging to clade 2.2. Avian Dis. 54, 538-547. doi: 10.1637/8790-040109-Reg.1

Hassan, K. E., Shany, S. A., Ali, A., Dahshan, A. H., El-Sawah, A. A., and El-Kady, M. F. (2016). Prevalence of avian respiratory viruses in broiler flocks in Egypt. Poult. Sci. 95, 1271-1280. doi: 10.3382/ps/pew068

Hassan, M. K., Jobre, Y., Arafa, A., Abdelwhab, E. M., Kilany, W. H., Khoulosy, S. G., et al. (2013). Detection of A/H5N1 virus from asymptomatic native ducks in mid-summer in Egypt. Arch. Virol. 158, 1361-1365. doi: $10.1007 / \mathrm{s} 00705-012-1599-\mathrm{x}$

Herfst, S., Schrauwen, E. J., Linster, M., Chutinimitkul, S., de Wit, E., Munster, V. J., et al. (2012). Airborne transmission of influenza A/H5N1 virus between ferrets. Science 336, 1534-1541. doi: 10.1126/science.1213362

Herrick, K. A., Huettmann, F., and Lindgren, M. A. (2013). A global model of avian influenza prediction in wild birds: the importance of northern regions. Vet. Res. 44:42. doi: 10.1186/1297-9716-44-42

Hoffmann, B., Hoffmann, D., Henritzi, D., Beer, M., and Harder, T. C. (2016), Riems influenza a typing array (RITA): an RT-qPCR-based low density array for subtyping avian and mammalian influenza a viruses. Sci. Rep. 6:27211. doi: 10.1038/srep27211

Hothorn, T., Bretz, F., and Westfall, P. (2008). Simultaneous inference in general parametric models. Biom. J. 50, 346-363. doi: 10.1002/bimj.200810425

Hulse-Post, D. J., Sturm-Ramirez, K. M., Humberd, J., Seiler, P., Govorkova, E. A., Krauss, S., et al. (2005). Role of domestic ducks in the propagation and biological evolution of highly pathogenic H5N1 influenza viruses in Asia. Proc. Natl. Acad. Sci. U.S.A. 102, 10682-10687. doi: 10.1073/pnas.0504662102

Kayali, G., Kandeil, A., El-Shesheny, R., Kayed, A. S., Maatouq, A. M., Cai, Z., et al. (2016). Avian Influenza A(H5N1) Virus in Egypt. Emerg. Infect. Dis. 22, 379-388. doi: 10.3201/eid2203.150593

Kim, J. K., Negovetich, N. J., Forrest, H. L., and Webster, R. G. (2009). Ducks: the "Trojan horses" of H5N1 influenza. Influenza Other Respir. Viruses 3, 121-128. doi: 10.1111/j.1750-2659.2009.00084.x

Klopfleisch, R., Werner, O., Mundt, E., Harder, T., and Teifke, J. P. (2006). Neurotropism of highly pathogenic avian influenza virus $\mathrm{A} /$ chicken/Indonesia/2003 (H5N1) in experimentally infected pigeons (Columbia livia f. domestica). Vet. Pathol. 43, 463-470. doi: 10.1354/vp.43-4-463

Lebarbenchon, C., Feare, C. J., Renaud, F., Thomas, F., and Gauthier-Clerc, M. (2010). Persistence of highly pathogenic avian influenza viruses in natural ecosystems. Emerg. Infect. Dis. 16, 1057-1062. doi: 10.3201/eid1607.090389

Lee, Y. J., Kang, H. M., Lee, E. K., Song, B. M., Jeong, J., Kwon, Y. K., et al. (2014). Novel reassortant influenza A(H5N8) viruses, South Korea, 2014. Emerg. Infect. Dis. 20, 1087-1089. doi: 10.3201/eid2006.140233

Li, J., Rao, Y., Sun, Q., Wu, X., Jin, J., Bi, Y., et al. (2015). Identification of climate factors related to human infection with avian influenza A H7N9 and H5N1 viruses in China. Sci. Rep. 5:18094. doi: 10.1038/srep18094

Li, K. S., Guan, Y., Wang, J., Smith, G. J., Xu, K. M., Duan, L., et al. (2004). Genesis of a highly pathogenic and potentially pandemic $\mathrm{H} 5 \mathrm{~N} 1$ influenza virus in eastern Asia. Nature 430, 209-213. doi: 10.1038/nature02746

Löndt, B. Z., Núñez, A., Banks, J., Alexander, D. J., Russell, C., RichardLöndt, A. C., et al. (2010). The effect of age on the pathogenesis of a highly pathogenic avian influenza (HPAI) H5N1 virus in Pekin ducks (Anas platyrhynchos) infected experimentally. Influenza Other Respir. Viruses 4, 17-25. doi: 10.1111/j.1750-2659.2009.00116.x

Löndt, B. Z., Nunez, A., Banks, J., Nili, H., Johnson, L. K., and Alexander, D. J. (2008). Pathogenesis of highly pathogenic avian influenza A/turkey/Turkey/1/2005 H5N1 in Pekin ducks (Anas platyrhynchos) infected experimentally. Avian Pathol. 37, 619-627. doi: 10.1080/030794508024 99126

Long, J. S., Benfield, C. T., and Barclay, W. S. (2015). One-way trip: influenza virus' adaptation to gallinaceous poultry may limit its pandemic potential. Bioessays 37, 204-212. doi: 10.1002/bies.201400133 
Loth, L., Gilbert, M., Wu, J., Czarnecki, C., Hidayat, M., and Xiao, X. (2011). Identifying risk factors of highly pathogenic avian influenza (H5N1 subtype) in Indonesia. Prev. Vet. Med. 102, 50-58. doi: 10.1016/j.prevetmed.2011.06.006

Murray, E. J., and Morse, S. S. (2011). Seasonal oscillation of human infection with influenza A/H5N1 in Egypt and Indonesia. PLoS ONE 6:e24042. doi: 10.1371/journal.pone.0024042

Naguib, M. M., Abdelwhab, E. M., and Harder, T. C. (2016a). Evolutionary features of influenza A/H5N1 virus populations in Egypt: poultry and human health implications. Arch. Virol. 161, 1963-1967. doi: 10.1007/s00705-016-2849-0

Naguib, M. M., Grund, C., Arafa, A. S., Abdelwhab, E. M., Beer, M., and Harder, T. C. (2017). Heterologous post-infection immunity against Egyptian avian influenza virus (AIV) H9N2 modulates the course of subsequent infection by highly pathogenic AIV H5N1, but vaccination immunity does not. J. Gen. Virol. 98, 1169-1173. doi: 10.1099/jgv.0.000767

Naguib, M. M., Hagag, N., El-Sanousi, A. A., Hussein, H. A., and Arafa, A. S. (2016b). The matrix gene of influenza A H5N1 in Egypt, 2006-2016: molecular insights and distribution of amantadine-resistant variants. Virus Genes 52, 872-876. doi: 10.1007/s11262-016-1373-3

OIE (2015). Chapter 2.3.4. - Avian Influenza. Available online at: http://www.oie. int/fileadmin/Home/fr/Health_standards/tahm/2.03.04_AI.pdf

Pantin-Jackwood, M. J., Smith, D. M., Wasilenko, J. L., Cagle, C., Shepherd, E., Sarmento, L., et al. (2012). Effect of age on the pathogenesis and innate immune responses in Pekin ducks infected with different H5N1 highly pathogenic avian influenza viruses. Virus Res. 167, 196-206. doi: 10.1016/j.virusres.2012.04.015

Pantin-Jackwood, M. J., and Swayne, D. E. (2009). Pathogenesis and pathobiology of avian influenza virus infection in birds. Rev. Off. Int. Epizoot. 28, 113-136. doi: $10.20506 /$ rst.28.1.1869

Pantin-Jackwood, M., Swayne, D. E., Smith, D., and Shepherd, E. (2013). Effect of species, breed and route of virus inoculation on the pathogenicity of $\mathrm{H} 5 \mathrm{~N} 1$ highly pathogenic influenza (HPAI) viruses in domestic ducks. Vet. Res. 44:62. doi: 10.1186/1297-9716-44-62

Pfeiffer, D. U., Minh, P. Q., Martin, V., Epprecht, M., and Otte, M. J. (2007). An analysis of the spatial and temporal patterns of highly pathogenic avian influenza occurrence in Vietnam using national surveillance data. Vet. J. 174, 302-309. doi: 10.1016/j.tvjl.2007.05.010

Pinheiro, J., Bates, D., DebRoy, S. D. S., and Team, R. C. (2017). nlme: Linear and Nonlinear Mixed Effects Models. R package version 3.1-131.Available online at: https://CRAN.R-project.org/package=nlme

$\mathrm{R}$ Core-Team (2015). R Development Core Team (2011). R: A Language and Environment for Statistical Computing. Vienna: the R Foundation for Statistical Computing. Available online at http://www.R-project.org/

Rohaim, M. A., El-Naggar, R. F., Hamoud, M. M., Nasr, S. A., Ismael, E., Laban, S. E., et al. (2017). Re-emergence of a novel H5N1 Avian influenza virus variant subclade 2.2.1.1 in Egypt during 2014. Transbound. Emerg. Dis. 64, 1306-1312. doi: $10.1111 /$ tbed.12472

Salaheldin, A. H., Veits, J., Abd El-Hamid, H. S., Harder, T. C., Devrishov, D., Mettenleiter, T. C., et al. (2017). Isolation and genetic characterization of a novel 2.2.1.2a H5N1 virus from a vaccinated meat-turkeys flock in Egypt. Virol. J. 14:48. doi: 10.1186/s12985-017-0697-5

Smith, G. J., Donis, R. O., World Health Organization/World Organisation for Animal Health/Food and Agriculture Organization, and (WHO/OIE/FAO) H5 Evolution Working Group (2015). Nomenclature updates resulting from the evolution of avian influenza A(H5) virus clades 2.1.3.2a, 2.2.1, and 2.3.4 during 2013-2014. Influenza Other Respir. Viruses 9, 271-276. doi: 10.1111/irv.12324

Songserm, T., Jam-on, R., Sae-Heng, N., Meemak, N., Hulse-Post, D. J., SturmRamirez, K. M., et al. (2006). Domestic ducks and H5N1 influenza epidemic, Thailand. Emerg. Infect. Dis. 12, 575-581. doi: 10.3201/eid1204.051614
Szeredi, L., Dan, A., Palmai, N., Ursu, K., Balint, A., Szeleczky, Z., et al. (2010). Tissue tropism of highly pathogenic avian influenza virus subtype H5N1 in naturally infected mute swans (Cygnus Olor), domestic geese (Aser Anser var. domestica), pekin ducks (Anas platyrhynchos) and mulard ducks (Cairina moschata x Anas platyrhynchos). Acta Vet. Hung. 58, 133-145. doi: 10.1556/AVet.58.2010.1.14

Terregino, C., Beato, M. S., Bertoli, E., Mancin, M., and Capua, I. (2009). Unexpected heat resistance of Italian low-pathogenicity and highpathogenicity avian influenza A viruses of $\mathrm{H} 7$ subtype to prolonged exposure at 37 degrees C. Avian Pathol. 38, 519-522. doi: 10.1080/03079450903350244

Venables, W. N., and Ripley, B. D. (2002). Modern Applied Statistics with S. New York, NY: Springer.

Vergne, T., Grosbois, V., Jobre, Y., Saad, A., El Nabi, A. A., Galal, S., et al. (2012). Avian influenza vaccination of poultry and passive case reporting, Egypt. Emerg. Infect. Dis. 18, 2076-2078. doi: 10.3201/eid1812.120616

Watanabe, Y., Ibrahim, M. S., Ellakany, H. F., Abd El-Hamid, H. S., and Ikuta, K. (2011a). Genetic diversification of H5N1 highly pathogenic avian influenza A virus during replication in wild ducks. J. Gen. Virol. 92, 2105-2110. doi: 10.1099/vir.0.032623-0

Watanabe, Y., Ibrahim, M. S., Ellakany, H. F., Kawashita, N., Mizuike, R., Hiramatsu, H., et al. (2011b). Acquisition of human-type receptor binding specificity by new H5N1 influenza virus sublineages during their emergence in birds in Egypt. PLoS Pathog. 7:e1002068. doi: 10.1371/journal.ppat.1002068

Williams, R. A., and Peterson, A. T. (2009). Ecology and geography of avian influenza (HPAI H5N1) transmission in the Middle East and northeastern Africa. Int. J. Health Geogr. 8:47. doi: 10.1186/1476-072X-8-47

Williams, R. A., Xiao, X. M., and Peterson, A. T. (2011). Continent-wide association of H5N1 outbreaks in wild and domestic birds in Europe. Geospat. Health 5, 247-253. doi: 10.4081/gh.2011.177

WHO (2017). Cumulative Number of Confirmed Human Cases of Avian Influenza A(H5N1) Reported to WHO. Available online at: http://www.who.int/ influenza/human_animal_interface/H5N1_cumulative_table_archives/en/ (Accessed December 10, 2017).

Younan, M., Poh, M. K., Elassal, E., Davis, T., Rivailler, P., Balish, A. L., et al. (2013). Microevolution of highly pathogenic avian influenza A(H5N1) viruses isolated from humans, Egypt, 2007-2011. Emerg. Infect. Dis. 19, 43-50. doi: 10.3201/eid1901.121080

Young, S. G., Carrel, M., Kitchen, A., Malanson, G. P., Tamerius, J., Ali, M., et al. (2017). How's the Flu Getting Through? Landscape genetics suggests both humans and birds spread H5N1 in Egypt. Infect. Genet. Evol. 49, 293-299. doi: 10.1016/j.meegid.2017.02.005

Yuan, R., Cui, J., Zhang, S., Cao, L., Liu, X., Kang, Y., et al. (2014). Pathogenicity and transmission of $\mathrm{H} 5 \mathrm{~N} 1$ avian influenza viruses in different birds. Vet. Microbiol. 168, 50-59. doi: 10.1016/j.vetmic.2013.10.013

Conflict of Interest Statement: The authors declare that the research was conducted in the absence of any commercial or financial relationships that could be construed as a potential conflict of interest.

Copyright (C) 2018 Salaheldin, Kasbohm, El-Naggar, Ulrich, Scheibner, Gischke, Hassan, Arafa, Hassan, Abd El-Hamid, Hafez, Veits, Mettenleiter and Abdelwhab. This is an open-access article distributed under the terms of the Creative Commons Attribution License (CC BY). The use, distribution or reproduction in other forums is permitted, provided the original author(s) and the copyright owner are credited and that the original publication in this journal is cited, in accordance with accepted academic practice. No use, distribution or reproduction is permitted which does not comply with these terms. 